the carotid ultrasound findings showed 110 patients with intermediate risk, 28 with high risk and 43 with a very high risk.

In table 1, the characteristics of the 43 patients whose carotid ultrasound findings resulted in a risk re-stratification vs the 138 with no risk modification.

\begin{tabular}{lcc}
\hline & $\begin{array}{c}\text { Risk modification due to } \\
\text { pathologic carotid } \\
\text { ultrasound }(\mathbf{n}=\mathbf{4 3})\end{array}$ & $\begin{array}{c}\text { No risk modification due to } \\
\text { pathologic carotid ultrasound } \\
(\mathbf{n}=138)\end{array}$ \\
\hline Sex (Woman) & $32(74 \%)$ & $90(65 \%)$ \\
Age (years) & $58,1( \pm 9)$ & $53,5( \pm 12)^{*}$ \\
Disease & $28(65 \%)$ & $68(49 \%)$ \\
RA $(n=96)$ & $6(14 \%)$ & $31(22 \%)$ \\
SpA $(n=37)$ & $9(21 \%)$ & $39(28 \%)$ \\
PsA ( $n=48)$ & & \\
DM & $4(9 \%)$ & $15(11 \%)$ \\
High blood pressure & $24(56 \%)$ & $54(39 \%)$ \\
Hypercholesterolemia & $30(70 \%)$ & $59(43 \%)^{*}$ \\
Smoker & $12(28 \%)$ & $26(19 \%)$ \\
Obesity & $31(72 \%)$ & $87(63 \%)$ \\
Modified SCORE & $2,7( \pm 1,6)$ & $2,3( \pm 1,7)$ \\
\hline${ }^{*}$ p $<0.05$ between group comparison &
\end{tabular}

Conclusions: Patients with risk modification due to carotid ultrasound findings were older and were more frequently hypercholesterolemic. Performing a carotid ultrasound in these patients seems to offer especially relevant information.

Disclosure of Interest: None declared

DOI: 10.1136/annrheumdis-2018-eular.4867

\section{SAT0652 STUDY OF NAIL UNIT WITH ULTRASONOGRAPHY IN SEVERAL RHEUMATOLOGICAL CONDITIONS: A CROSS SECTIONAL STUDY OF DISTAL INTERPHALANGEAL JOINT AND NAIL}

G. Adami, E. Vantaggiato, C. Benini, A. Fassio, A. Giollo, G. Orsolini, L. Idolazzi, D. Gatti. Rheumatology Unit, University of Verona, Verona, Italy

Background: The ultrasonography (US) is a feasible technique when you refer to the peripheral small joints and also to the nail. ${ }^{1}$ DIP joints are not only affected by inflammatory disease and a more frequent condition is osteoarthritis (OA). The bone and synovial changes due to this condition are very similar to the ones of PSA especially regarding osteoproliferative lesions.

Objectives: The aim of our study was exploring through imaging the changes of nail and enthesis of extensor tendon of the finger in inflammatory and degenerative conditions in order to find structural differences of nail and DIP.

Methods: This is an observational study on PSO, PSA, RA or OA patients. A control group of 50 healthy volunteers was used for comparison. Diagnosis was based on clinical or scientific criteria, such as CASPAR or EULAR/ACR were applicable. The study sample included 203 individual. The ultrasonographers were blind to clinical data and diagnosis of the patient. The ultrasound examination was done with a GE Logiq S8. The structural alterations of the plate were evaluated using a semiquantitative score for the magnitude of the alteration. The score provides values from 0 (no alteration) to 3 (severly altered). A semiquantitative approach was also used for evaluation of the power Doppler signal.

Results: The study sample was composed by 51 patients affected by PsA, 31 affected by PSO group, 37 subjects with RA, 34 with OA and $50 \mathrm{HC}$. The analysis of nail bed PDUS revealed an unusual trend for patients affected by OA who showed a prevalence of lesions of every grade but a lower rate of normal cases. The evaluation of the PDUS of the enthesis revealed that patients affected by PsA have an increased rate of PDUS signal at the enthesis of the extensor tendon. Considering nail plate $\mathrm{HC}$ showed a strong difference ( $\mathrm{p}$ value $<0.001$ ) vs all groups except for patients affected by RA. Regarding nail bed thickness HC showed difference only if compared with PSA or OA group. $\mathrm{P}$ values are reported in table 1.

\begin{tabular}{llccccc}
\hline & & PSO & PSA & RA & OA & HC \\
\hline Nail plate & PSO & $/ /$ & 0.99 & 0.021 & 0.99 & $<0.001$ \\
Thickness & PSA & 0.99 & $/ /$ & 0.002 & 0.99 & $<0.001$ \\
& RA & 0.021 & 0.002 & $/ /$ & 0.06 & 0.06 \\
& OA & 0.99 & 0.99 & 0.06 & $/ /$ & $<0.001$ \\
& HC & $<0.001$ & $<0.001$ & 0.06 & $<0.001$ & $/ /$ \\
Nail bed & PSO & $/ /$ & 0.99 & 0.003 & $<0.001$ & 0.15 \\
Thickness & PSA & 0.99 & $/ /$ & $<0.001$ & $<0.001$ & 0.002 \\
& RA & 0.003 & $<0.001$ & $/ /$ & 0.69 & 0.12 \\
& OA & $<0.001$ & $<0.001$ & 0.69 & $/ /$ & 0.012 \\
& HC & 0.15 & 0.002 & 0.12 & 0.012 & $/ /$ \\
\hline
\end{tabular}

Conclusions: The data support the concept that nail enthesis unit is in some way involved in different pathological conditions. No exclusive feature belongs only to one or another disease, but the data provided suggested that peculiar lesions might be found only in certain disease and in certain structures, like the entheses.
The US of the nail should be considered as one of the possible and promising approach in the study of these structures.

\section{REFERENCE:}

[1] Arbault A, Devilliers $H$, Laroche D, et al. Reliability, validity and feasibility of nail ultrasonography in psoriatic arthritis. Jt Bone Spine Rev Rhum 2016;83:539-44. doi:10.1016/j.jbspin.2015.11.004

Disclosure of Interest: None declared

DOI: 10.1136/annrheumdis-2018-eular.6992

\section{SAT0653 RELATIONSHIP BETWEEN CARDIAC VALVULAR CALCIFICATION, CAROTID ATHEROSCLEROSIS, AND CORONARY CALCIFICATION IN PATIENTS WITH RHEUMATOID ARTHRITIS}

H. Udachkina, D. Novikova, T. Popkova, E. Markelova, I. Kirillova, E. Gerasimova. V.A. Nasonova Research Institute of Rheumatology, Moscow, Russian Federation

Background: The prevalence and relationship of VC with arterial atherosclerosis in patients with rheumatoid arthritis (RA) is under-investigated.

Objectives: investigate the prevalence of $\mathrm{VC}$ in patients with RA and its relationship with carotid atherosclerosis (CA) and coronary artery calcification (CAC).

Methods: Study population was consisted of 128 adult patients $(65.6 \%$ women, age $55^{43 ; 61}$ years) with RA according to ACR/EULAR criteria (disease duration $6^{5 ; 18}$ month) with moderate/high RA activity (DAS28 5.3 [5.0; 6.1]). Arterial hypertension $(\mathrm{AH})$ was found in $64 \%$, ischaemic heart disease (IHD) - in $14 \%$, dyslipidemia - in $54.7 \%$, smoking - in $20.3 \%$, diabetes mellitus type 2 - in $7 \%$, myocardial infarction - in $1.6 \%$, stroke - in $1.6 \%$. Cardiac VC was evaluated by transthoracic echocardiography; CAC scoring was done with 32-row scanner by standard Agatston method; CA was evaluated with duplex ultrasound.

Results: Patients were divided on 3 groups depending on valve condition: normal $(34.3 \%)$; leaves thickening $(30.5 \%)$; VC $(35.25 \%)$. The VC group consisted of isolated mitral VC - in 11\%, isolated aortic VC - in 51\%, calcification of both valve in $38 \%$. Mitral regurgitation (3 degree) was detected in $0.8 \%$ patient, mitral stenosis (mild) $-0.8 \%$, aortic regurgitation (1 degree) - in $25 \%$, aortic stenosis (mild) in $0.8 \%$. Age, BMI, SBP and frequency of $\mathrm{AH}, \mathrm{IHD}, \mathrm{CA}, \mathrm{CAC}$ significant increased from 1 to 3 group $(p<0.05)$. There was no significant difference in the sex, lipid levels, Rg-stage, RA duration and level of parameters of RA activity (DAS28, CRP ESR) between investigated groups.

\begin{tabular}{lccc}
\hline & $\begin{array}{c}\text { Normal valve } \\
(\mathrm{n}=44)\end{array}$ & $\begin{array}{c}\text { Thickening } \\
(\mathrm{n}=39)\end{array}$ & $\begin{array}{c}\text { Calcification } \\
(\mathrm{n}=45)\end{array}$ \\
\hline $\mathrm{Age}$ & $39.5^{29 ; 51}$ & $56.5[51.5 ; 62]$ & $60^{57 ; 67}$ * \\
$\mathrm{BMI}$ & $23.4[21.4 ; 28.6]$ & $26.3[23.7 ; 29.3]$ & $27.2^{25 ; 31 *}$ \\
$\mathrm{SBP}$ & $120^{100 ; 130}$ & $120^{110 ; 134}$ & $130^{120 ; 140 *}$ \\
$\mathrm{AH}$ & $19(43.2)$ & $23(59)$ & $40(88.9) *$ \\
$\mathrm{IHD}$ & $1(2.3)$ & $6(15.4)$ & $11(24.4) *$ \\
$\mathrm{CA}$ & $12(27.3)$ & $30(77)$ & $39(86.7)$ * \\
CAC & $8(18.2)$ & $16(41)$ & $32(71.1) *$ \\
\hline Note: Data are expressed as median $[25$ percentile;75 percentile] for continuous variables
\end{tabular}

and as a number $(\%)$ for the categorical variables. ${ }^{*}$ Difference for trend $(p<0.05)$

Conclusions: Among RA patients, more than half have a modified valve struc ture and in $1 / 3$ of them VC. The presence of VC is correlated with traditional cardiovascular risk factors, but not with lipid levels, activity and severity of RA. The probability of CA and CAC presence is significantly increased when there is VC. Disclosure of Interest: None declared DOI: 10.1136/annrheumdis-2018-eular.5447

\section{SAT0654 ASSOCIATION OF PREDNISONE AND ANTIMALARIALS AND ECHOCARDIOGRAPHIC FINDINGS IN ASYMPTOMATIC CARDIOVASCULAR PATIENTS WITH SLE}

I. Jochims, L.M.H. Mota, L. Muniz , D.F. Vasconcelos, L.L. Santos-Neto. UNIVERSITY OF BRASILIA, Brasilia, Brazil

Background: Systemic lupus erythematosus (SLE) is an autoimmune inflammatory disease that presents with increase of cardiovascular risk. Echocardiogram can detect morphofunctional cardiac changes and predict clinical outcomes in patients with SLE1.

Objectives: To evaluate echocardiographic morphofunctional parameters in women with SLE, using conventional echocardiogram and to relate the echocardiographic findings to disease-related factors and therapeutics.

Methods: We have selected 51 women with SLE, without cardiovascular symptoms, under regular medical follow-up. Patients who had limitations to do echocardiography, smokers, and those with a creatinine level higher than $1.5 \mathrm{mg} / \mathrm{dL}$ were 
excluded. 51 patients were divided into two groups, patients with SLEDAI $<6$ $(n=30)$ and with SLEDAI $\geq 6(n=21)$. They were submitted to clinical evaluation, laboratory tests and a traditional echocardiogram.

Results: Patients presented an average age of 34.5 years and average time of diagnosis of SLE of 7.2 years. In the comparison between groups, patients with SLEDAI $>6$ had a higher daily dose of prednisone $(p=0.0016)$, more hospitalizations in the last 12 months $(p=0.0173)$, and a higher cumulative dose of pulse therapy with methylprednisolone $(p=0.008)$. Patients with SLEDAI $<6$ had a longer average time of antimalarials (AM) use $(p=0.0309)$. Regarding the echocardiographic parameters, group with SLEDAI $\geq 6$ presented greater left ventricular mass ( $L V M, p=0.0156)$, thickness of ventricular septum $(p=0.0106)$ and left ventricular posterior wall (LVPW, $p=0.0273$ ). In multivariate analysis the LVM presented a positive association with age $(p=0.0160)$, current daily dose of prednisone $(p=0.0009)$ and time of AM use $(p=0.0026), r^{2} 0.3625$. Regarding the thickness of the interventricular septum, there was a positive association with age $(p<0.0001)$, current dose of prednisone $(p<0.0001)$, SLEDAI $(p=0.02)$, SLICC $(p=0.0093)$ and pulse with methylprednisolone $(p=0.0062)$, with $r^{2} 0.6983$. There is a positive association of daily dose of prednisone with the parameters LVPW, LVM and septum thickness and AM was a predictor of greater LVM.

Conclusions: Several factors may contribute to cardiac morphofunctional changes in SLE. Ventricular hypertrophy in asymptomatic cardiovascular patients was not related to the use of prednisone or time of AM use in other studies, however these factors should be taken into account. There are no adequate study designs in literature to evaluate the effect of high doses of corticosteroids and time of AM use on cardiac morphology and function. AM induced cardiomyopathy is a rare, probably under-recognised, complication of prolonged AM treatment, it presents as a hypertrophic, restrictive cardiomyopathy with or without conduction abnormalities. Early recognition and drug withdrawal are critical with a survival rate of almost $55 \%{ }^{2}$. Longitudinal studies are needed to determine the effect of prednisone and AM use in subclinical echocardiographic findings to avoid unfavourable cardiovascular outcomes.

\section{REFERENCES :}

[1] Chen J, et al. Heart involvement in systemic lupus erythematosus:a sys temic review and meta-analysis. Clin Rheumatol 2016;35:2437-48.

[2] Tselios K, et al. Antimalarial-induced cardiomyopathy: a systematic review of the literature. Lupus 2017;0:1-9.

Disclosure of Interest: None declared

DOI: 10.1136/annrheumdis-2018-eular.6043

\section{SAT0655 MYOSITIS AND FASCIITIS BY MAGNETIC RESONANCE IMAGING IN RECENT-ONSET POLYMYALGIA RHEUMATICA AND EFFECT OF TOCILIZUMAB THERAPY}

J.P. Laporte ${ }^{1}$, F. Garrigues ${ }^{1}$, A. Huwart ${ }^{1}$, S. Jousse-Joulin ${ }^{2}$, T. Marhadour ${ }^{3}$, D. Guellec ${ }^{3}$, D. Cornec ${ }^{2}$, V. Devauchelle-Pensec ${ }^{2}$, A. Saraux ${ }^{3} .{ }^{1}$ Radiology, $\mathrm{CHU}$ Brest and Université Bretagne Occidentale; ${ }^{2}$ Rheumatology, CHU Brest and UMR 1227 Université Bretagne Occidentale; ${ }^{3}$ Rheumatology, CHU Brest and Université Bretagne Occidentale, Brest, France

Background: In everyday practice, myofascial lesions are not usually evaluated on MRls obtained for patients with PMR.

Objectives: To assess the prevalence of myofascial inflammatory lesions visible by magnetic resonance imaging (MRI) and their changes after tocilizumab therapy in active polymyalgia rheumatica (PMR)

Methods: We conducted a post hoc analysis of data from the TENOR study of tocilizumab monotherapy in PMR. ${ }^{1}$ The 18 patients each received tocilizumab injections at weeks 0,4 , and 8 . The shoulder and pelvic girdles were assessed at baseline then at weeks 2 and 12 using T1- and T2-STIR-weighted MRI. Radiologists blinded to patient data assessed each muscle group for myositis and fasciitis on baseline, week-2, and week-12 MRIs. Reproducibility was estimated by having two radiologists assess the week- $2 \mathrm{MRIs}$ of 13 patients then computing the kappa coefficient.

Results: For myofascial lesion detection, intraobserver reproducibility was almost perfect $(\kappa=0.890)$ and interobserver reproducibility was substantial $(\kappa=0.758)$. At baseline, all patients had at least one inflammatory myofascial lesion (example on right shoulder fig 1); sites involved were the shoulder in 10 $(71.4 \%)$ patients, hip in $13(86.7 \%)$, ischial tuberosity in $9(60.0 \%)$, and pubic symphysis in $12(80.0 \%)$. Sites involved at week 12 were the shoulder in 8 $(53.3 \%)$ patients, hip in $5(33.3 \%)$, ischial tuberosity in 1, and pubic symphysis in 3 $(20.0 \%)$. At week 12 , of 103 muscle groups studied in all, $43(41.7 \%)$ had no inflammatory lesions, compared to 33 at baseline (Mac Nemar; $p<0.001$ ) but some areas seemed to be more responsive to tocilizumab compared to other areas. Improvements were noted in $66(64.1 \%)$ muscle groups, worsening in 2 $(1.9 \%)$, no change in $35(34.0 \%)$.

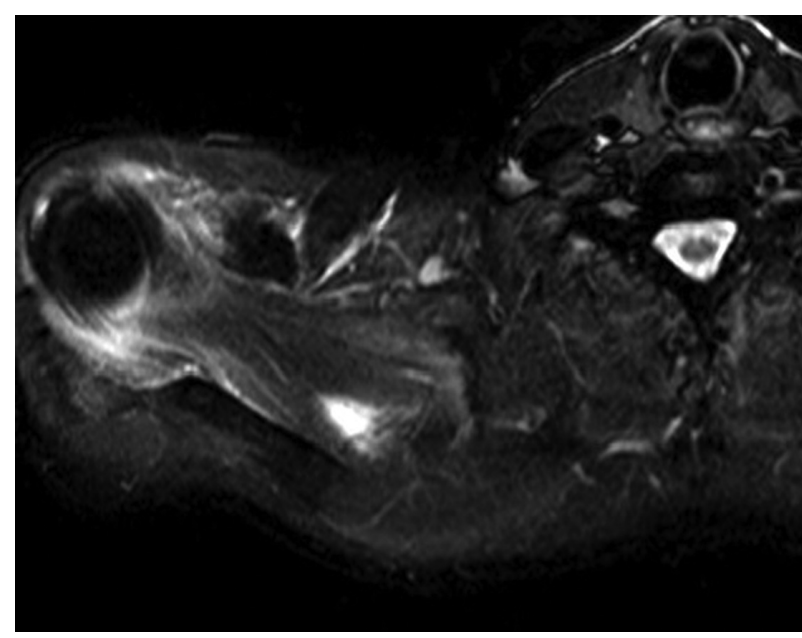

Conclusions: Myositis and fasciitis are common in recent-onset PMR and improve during tocilizumab therapy. They could be used for the diagnosis in routine practice and as criteria of outcome evaluation.

\section{REFERENCES:}

[1] Devauchelle-Pensec V, Berthelot JM, Cornec D, Renaudineau Y, Marhadour $\mathrm{T}$, Jousse-Joulin $\mathrm{S}$, et al. Efficacy of first-line tocilizumab therapy in early polymyalgia rheumatica: a prospective longitudinal study. Ann Rheum Dis 2016;75:1506-1510.

Disclosure of Interest: J. P. Laporte: None declared, F. Garrigues: None declared, A. Huwart: None declared, S. Jousse-Joulin: None declared, T. Marhadour: None declared, D. Guellec: None declared, D. Cornec: None declared, V. Devauchelle-Pensec: None declared, A. Saraux Grant/research support from: Chugai, Speakers bureau: Chugai DOI: 10.1136/annrheumdis-2018-eular.3065

\section{SAT0656 CIRCULATING MIR-99B-5P IS A MARKER OF INFLAMMATION AND STRUCTURAL DAMAGE ON MR IN EARLY RHEUMATOID ARTHRITIS}

J. Yue $^{1}$, F. Xiao ${ }^{2}$, J. Xu ${ }^{3}$, P.C. Wong ${ }^{1}$, E.K. Li ${ }^{1}$, L.P. Tam ${ }^{1}$, M. Li ${ }^{1}$, L. Qin ${ }^{3}$, J. F. Griffith ${ }^{2}$, L.-S. Tam ${ }^{1} .{ }^{1}$ The department of Rheumatology; ${ }^{2}$ Department of Imaging and Interventional Radiology, ${ }^{3}$ Department of Orthopedics and Traumatology, The Prince of Wales Hospital, The Chinese University of Hong Kong, Hongkong, Hong Kong

Background: Expression of several miRNAs occurs in the plasma and synovial fluid of patients with established rheumatoid arthritis (RA). We found that microRNA-143-3 p (miR-143-3 p), miR-145-5 p, and miR-99b-5p expression was associated with greater erosion volume in early RA (ERA) EULAR 2018 -abstract no 1980). Whether these miRNAs are associated with bone erosion and joint inflammation on magnetic resonance imaging (MRI) is unknown.

Objectives: To determine whether plasma cell-free circulating miRNAs are associated with (a) bone erosion and (b) inflammation severity on MRI in patients with ERA.

Methods: 66 ERA patients were recruited at presentation for this cross-sectional study. 60 of these 66 patients $(90.9 \%)$ were treatment naïve. MRI of the most severely affected wrist was performed in all patients. The degree of bone damage (i.e. erosions), bone inflammation (osteitis) and soft tissue inflammation (synovitis/tenosynovitis) was scored on MRI (a) semi-quantitatively using the Rheumatoid Arthritis MRI score (RAMRIS) for scoring the severity of erosions, bone marrow oedema, synovitis and tenosynovitis; and (b) quantitatively by measuring synovial and tenosynovial volume $\left(\mathrm{mm}^{3}\right)$. The three most dysregulated miRNAs (miR-143-3 p, miR-145-5 p, and miR-99b-5p) identified in our previous ERA study were validated by $\operatorname{TaqMan}^{\oplus} \mathrm{qRT}$-PCR in all patients.

Results: Expression of miR-99b-5p was higher in ERA patients with erosions $(1.28 \pm 0.61)$ on $M R I$ than those without erosions $(0.23 \pm 0.43, p<0.05)$. Subdivided according to mean RAMRIS synovitis score (5.69), miR-99b-5p expression was higher in ERA patients with relatively more synovitis $(0.75 \pm 1.24)$ on $M R I$ than those with relatively less synovitis $(0.34 \pm 1.14, p<0.05)$. Bone marrow oedema or tenosynovitis on MRI were not found to be associated with specific miRNA expression. Expression of miR-99b-5p did, however, correlate with synovial $(r=0.443, p=0.018)$ and tenosynovial volume $(r=0.423, p=0.025)$ on MRI. Linear regression analysis revealed miR-99b-5p expression to be independently associated with both increased synovial volume $(B=15.65,95 \% \mathrm{Cl} 3.42 \sim 27.89$, 